\title{
Pancreatic Neuroendocrine Tumor cM0 TNM Finding v8
}

National Cancer Institute

\section{Source}

National Cancer Institute. Pancreatic Neuroendocrine Tumor CMO TNM Finding v8. NCI Thesaurus. Code C135539.

Pancreatic neuroendocrine tumor without evidence of distant metastasis. (from AJCC 8th Ed.) 